Supporting Information for

\title{
Number of Reactive Charge Carriers - a Hidden Linker between Band Structure and Catalytic Performance in Photocatalysts
}

\footnotetext{
Jiadong Xiao, ${ }^{\dagger, \star,, \perp}$ Qingzhen Han, ${ }^{\dagger}$ Hongbin Cao, ${ }^{\dagger}$ Jabor Rabeah, ${ }^{*}$, Jin Yang $^{\dagger}{ }^{\dagger}$ Zhuang Guo, $^{\dagger, *}$ Linbi Zhou, ${ }^{\dagger}$ Yongbing $\mathrm{Xie}^{*, \dagger}$ and Angelika Brückner*,§
}

\footnotetext{
${ }^{\dagger}$ Beijing Engineering Research Center of Process Pollution Control, Division of Environment Technology and Engineering, Institute of Process Engineering, Chinese Academy of Sciences, Beijing 100190, China

* University of Chinese Academy of Sciences, Beijing 100049, China

$\S$ Leibniz-Institute for Catalysis e. V., at the University of Rostock, Albert-Einstein-Straße 29a, D-18059 Rostock, Germany.

${ }^{\perp}$ Inorganic Chemistry and Catalysis, Debye Institute for Nanomaterials Science, Utrecht University, David de Wiedgebouw, Universiteitsweg 99, 3584 CG Utrecht, The Netherlands.
}

*To whom correspondence should be addressed: Angelika.Brueckner@catalysis.de (A. Brückner); ybxie@ipe.ac.cn (Y.Xie); Jabor.Rabeah@catalysis.de (J. Rabeah). 


\section{Table of Contents}

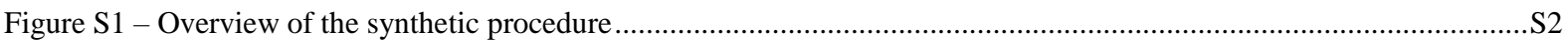

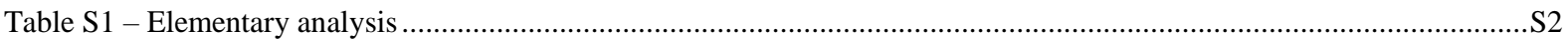

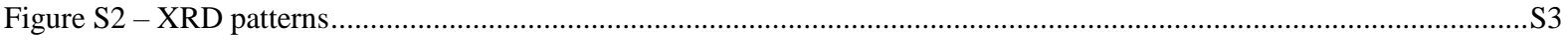



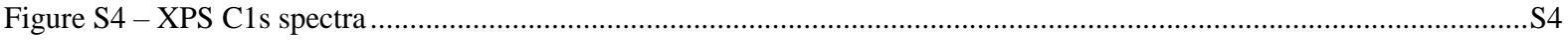



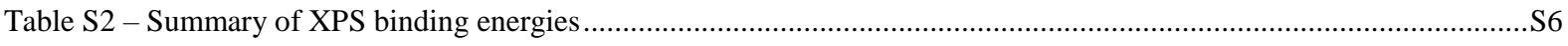

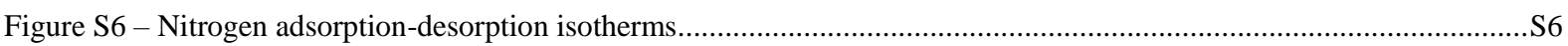

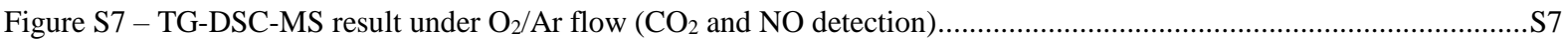

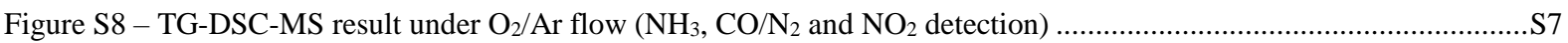

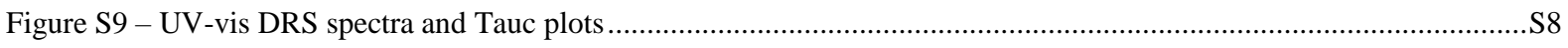

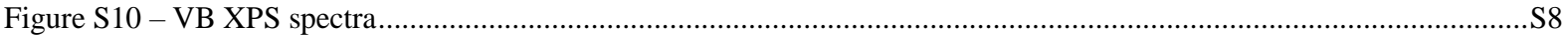

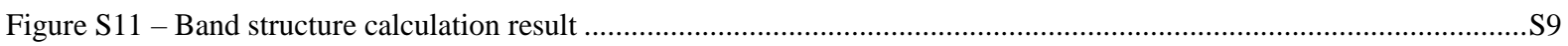

Figure S12 -OA degradation in the presence of tert-butyl alcohol (TBA) and under Vis $/ \mathrm{N}_{2} / \mathrm{g}_{-} \mathrm{C}_{3} \mathrm{~N}_{4} / \mathrm{Ag}^{+}$conditions ...........S9

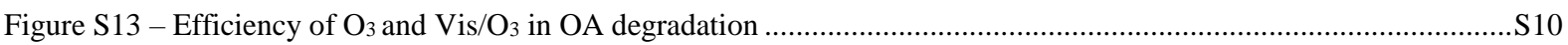

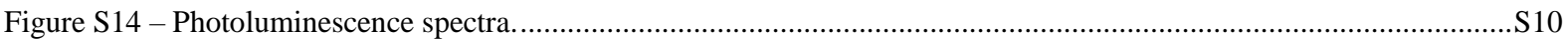

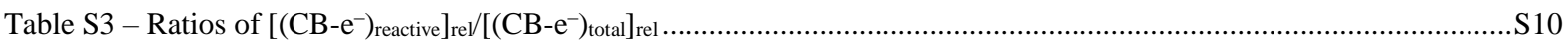

Figure S15 - Comparison of the integral areas of light absorption spectra between Ar-640-Air-550 and bulk...................S11

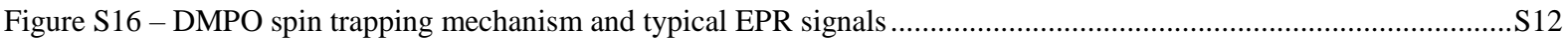

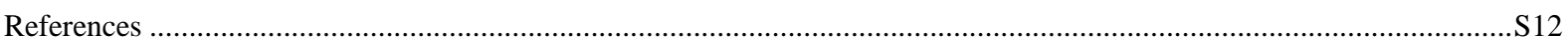




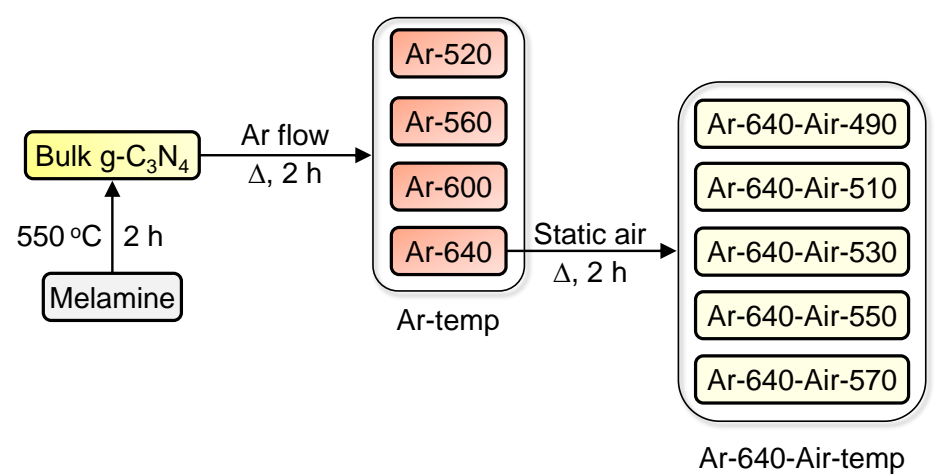

Figure S1. Overview of the synthetic procedure of $\mathrm{g}-\mathrm{C}_{3} \mathrm{~N}_{4}$ in this work.

Table S1. Elemental compositions and chemical formulas of the synthesized $g-C_{3} N_{4}$

\begin{tabular}{llllll}
\hline Sample & $\mathrm{C} / \mathrm{wt} \%$ & $\mathrm{~N} / \mathrm{wt} \%$ & $\mathrm{H} / \mathrm{wt} \%$ & $\mathrm{Chemical}_{\text {formula }}$ & C/N molar ratio \\
\hline Bulk g-C $\mathrm{C}_{3} \mathrm{~N}_{4}$ & $35.17 \pm 0.01$ & $62.22 \pm 0.01$ & $1.67 \pm 0.05$ & $\mathrm{C}_{3} \mathrm{~N}_{4.55} \mathrm{H}_{1.71}$ & $0.659 \pm 0.000$ \\
Ar-520 & $35.28 \pm 0.04$ & $62.14 \pm 0.03$ & $1.39 \pm 0.03$ & $\mathrm{C}_{3} \mathrm{~N}_{4.53} \mathrm{H}_{1.42}$ & $0.662 \pm 0.001$ \\
Ar-560 & $35.15 \pm 0.00$ & $61.49 \pm 0.11$ & $1.36 \pm 0.02$ & $\mathrm{C}_{3} \mathrm{~N}_{4.50} \mathrm{H}_{1.39}$ & $0.667 \pm 0.001$ \\
Ar-600 & $35.46 \pm 0.11$ & $61.46 \pm 0.15$ & $1.24 \pm 0.02$ & $\mathrm{C}_{3} \mathrm{~N}_{4.46} \mathrm{H}_{1.26}$ & $0.673 \pm 0.000$ \\
Ar-640 & $35.56 \pm 0.04$ & $60.69 \pm 0.02$ & $1.36 \pm 0.03$ & $\mathrm{C}_{3} \mathrm{~N}_{4.39} \mathrm{H}_{1.38}$ & $0.684 \pm 0.000$ \\
Ar-640-Air-490 & $34.10 \pm 0.07$ & $60.20 \pm 0.07$ & $1.63 \pm 0.01$ & $\mathrm{C}_{3} \mathrm{~N}_{4.54} \mathrm{H}_{1.72}$ & $0.661 \pm 0.001$ \\
Ar-640-Air-510 & $34.18 \pm 0.16$ & $60.23 \pm 0.31$ & $1.61 \pm 0.00$ & $\mathrm{C}_{3} \mathrm{~N}_{4.53} \mathrm{H}_{1.70}$ & $0.662 \pm 0.000$ \\
Ar-640-Air-530 & $34.62 \pm 0.10$ & $60.94 \pm 0.04$ & $1.55 \pm 0.02$ & $\mathrm{C}_{3} \mathrm{~N}_{4.53} \mathrm{H}_{1.61}$ & $0.663 \pm 0.002$ \\
Ar-640-Air-550 & $34.57 \pm 0.09$ & $60.78 \pm 0.04$ & $1.53 \pm 0.03$ & $\mathrm{C}_{3} \mathrm{~N}_{4.52} \mathrm{H}_{1.59}$ & $0.664 \pm 0.001$ \\
Ar-640-Air-570 & $34.79 \pm 0.08$ & $60.96 \pm 0.01$ & $1.46 \pm 0.04$ & $\mathrm{C}_{3} \mathrm{~N}_{4.51} \mathrm{H}_{1.51}$ & $0.666 \pm 0.001$ \\
\hline
\end{tabular}



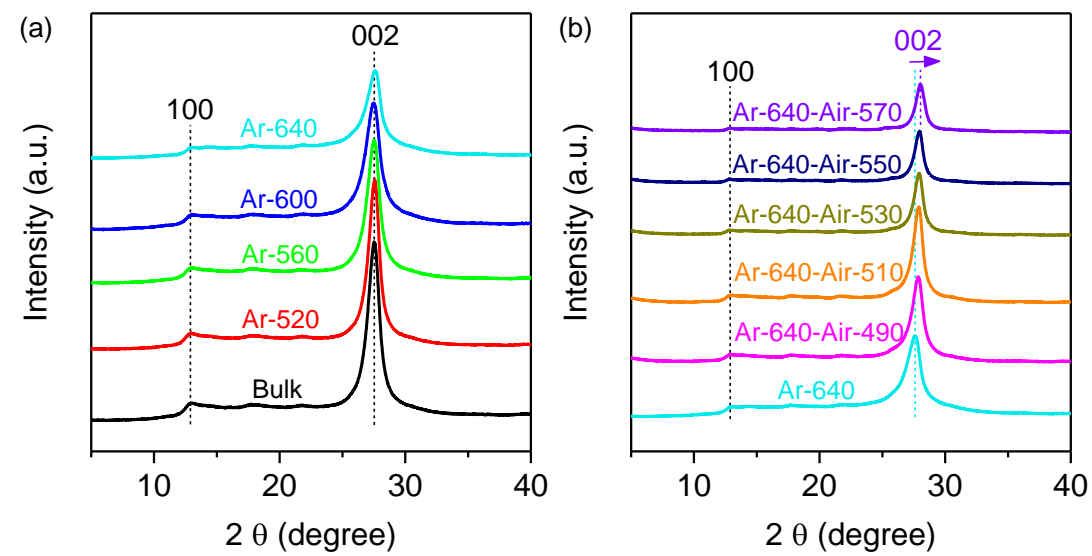

Figure S2. XRD patterns of (a) Ar-temp and (b) Ar-640-Air-temp samples.

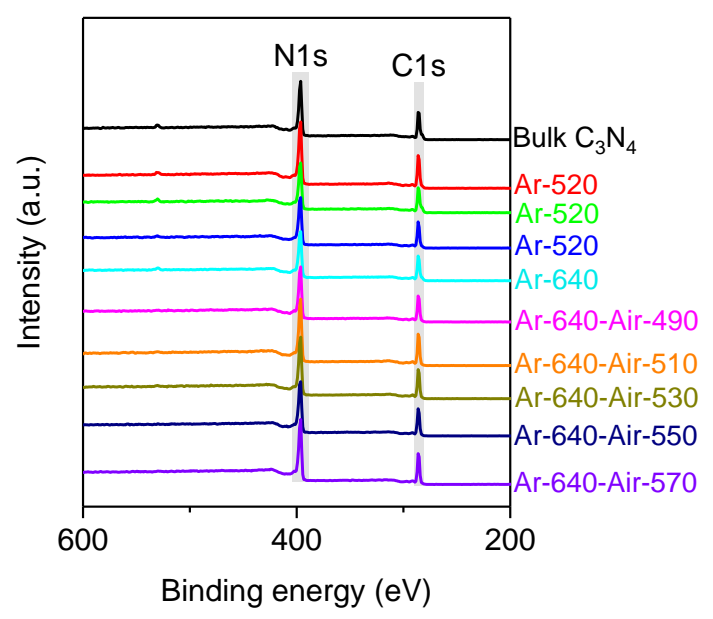

Figure S3. XPS survey spectra of various $\mathrm{g}-\mathrm{C}_{3} \mathrm{~N}_{4}$ materials. 

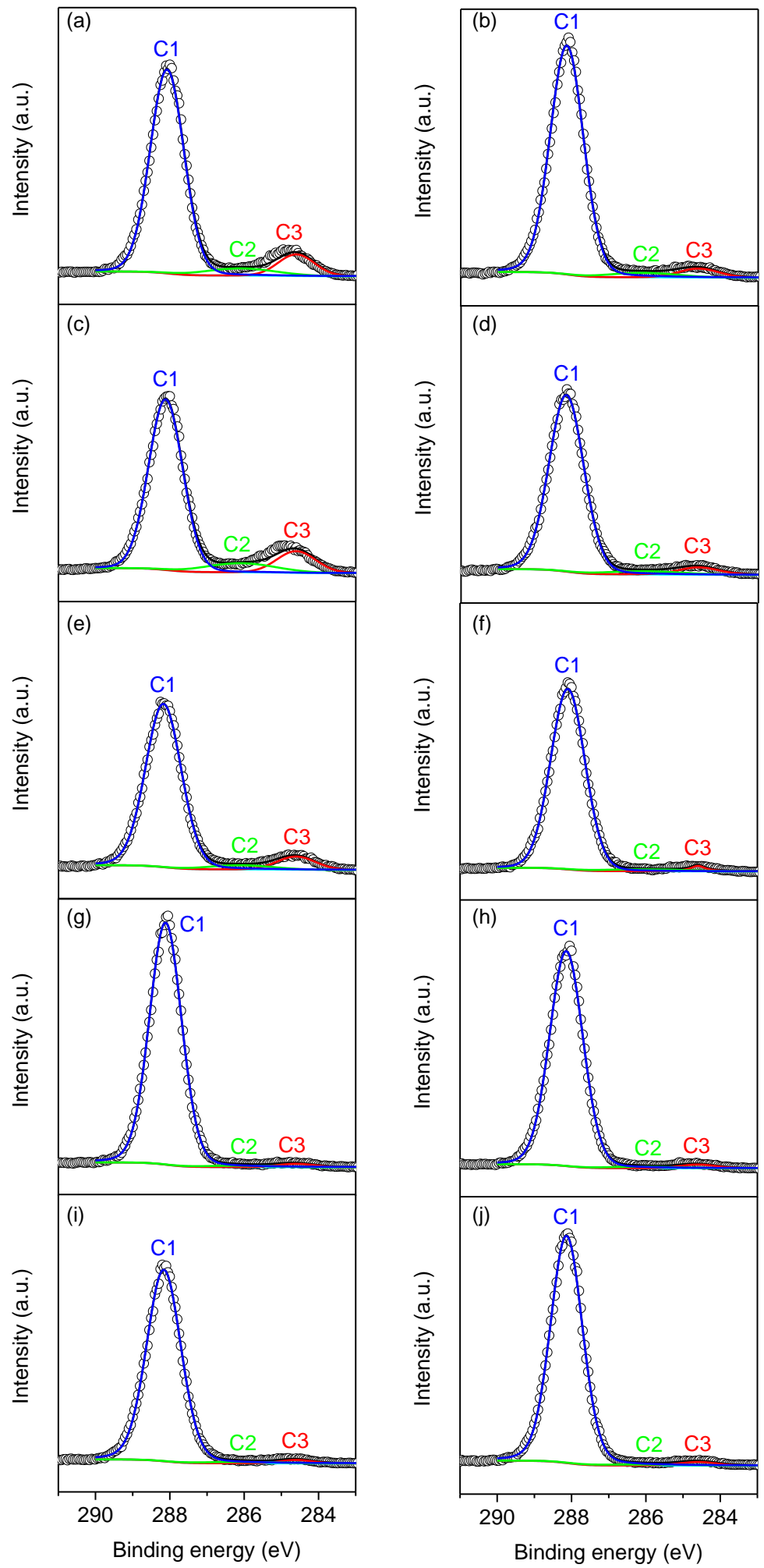

Figure S4. XPS C1s spectra of various g- $\mathrm{C}_{3} \mathrm{~N}_{4}$ materials: (a) bulk $\mathrm{g}-\mathrm{C}_{3} \mathrm{~N}_{4}$; (b) $\mathrm{Ar}-520$; (c) $\mathrm{Ar}-560$; (d) $\mathrm{Ar}-600$; (e) Ar-640; (f) Ar-640-Air-490; (g) Ar-640-Air-510; (h) Ar-640-Air-530; (i) Ar-640-Air-550; (j) Ar-640-Air570. 

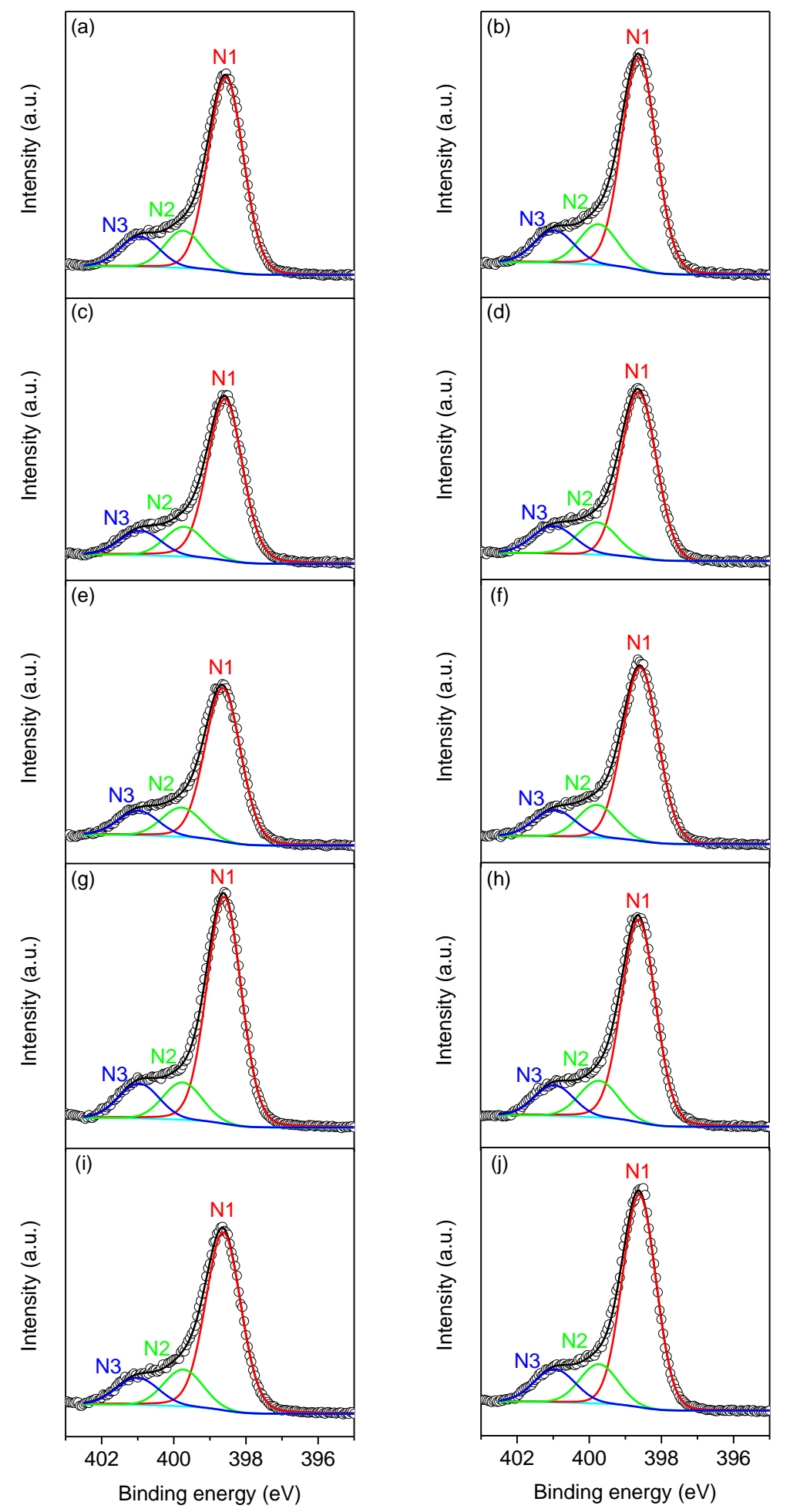

Figure S5. XPS N1s spectra of various g- $\mathrm{C}_{3} \mathrm{~N}_{4}$ materials: (a) bulk g- $\mathrm{C}_{3} \mathrm{~N}_{4}$; (b) Ar-520; (c) Ar-560; (d) Ar-600; (e) Ar-640; (f) Ar-640-Air-490; (g) Ar-640-Air-510; (h) Ar-640-Air-530; (i) Ar-640-Air-550; (j) Ar-640-Air570. 
Table S2. Binding energies of different $\mathrm{C}$ and $\mathrm{N}$ species in $\mathrm{g}-\mathrm{C}_{3} \mathrm{~N}_{4}$.

\begin{tabular}{|c|c|c|c|c|c|c|}
\hline \multirow{2}{*}{ Sample } & \multicolumn{6}{|c|}{ Binding energy (eV) } \\
\hline & $\mathrm{C} 1$ & $\mathrm{C} 2$ & $\mathrm{C} 3$ & N1 & $\mathrm{N} 2$ & N3 \\
\hline Bulk $\mathrm{C}_{3} \mathrm{~N}_{4}$ & 288.1 & 286.1 & 284.6 & 398.6 & 399.7 & 401.0 \\
\hline Ar-520 & 288.1 & 286.1 & 284.6 & 398.6 & 399.7 & 401.0 \\
\hline Ar-560 & 288.1 & 286.1 & 284.6 & 398.6 & 399.7 & 400.9 \\
\hline Ar-600 & 288.2 & 286.1 & 284.6 & 398.6 & 399.8 & 401.0 \\
\hline Ar-640 & 288.2 & 286.1 & 284.6 & 398.6 & 399.8 & 401.0 \\
\hline Ar-640-Air-490 & 288.1 & 286.1 & 284.6 & 398.6 & 399.8 & 401.0 \\
\hline Ar-640-Air-510 & 288.1 & 286.1 & 284.6 & 398.6 & 399.8 & 401.0 \\
\hline Ar-640-Air-530 & 288.1 & 286.1 & 284.6 & 398.6 & 399.7 & 401.0 \\
\hline Ar-640-Air-550 & 288.1 & 286.1 & 284.6 & 398.6 & 399.7 & 401.0 \\
\hline Ar-640-Air-570 & 288.1 & 286.1 & 284.6 & 398.6 & 399.7 & 401.0 \\
\hline
\end{tabular}

The dominant $\mathrm{C}$ 1s peak centered at $288.1 \mathrm{eV}$ (labelled as $\mathrm{C} 1$ ) originates from $\mathrm{sp}^{2}$-hybridized carbon in the aromatic ring. ${ }^{1}$ Other two weak peaks centered at $286.1 \mathrm{eV}$ (labelled as C2) and $284.6 \mathrm{eV}$ (labelled as $\mathrm{C} 3$, as reference) correspond to the $\mathrm{C}-\mathrm{NH}_{2}$ and $\mathrm{C}-\mathrm{C}$ species (adventitious carbon) in $\mathrm{g}-\mathrm{C}_{3} \mathrm{~N}_{4}$, respectively. ${ }^{2}$ The deconvolution of the overlapped $\mathrm{N} 1 \mathrm{~s}$ peaks has produced three peaks centered at ca. 398.6 (labelled as N1), 399.7 (labelled as N2), and $401.0 \mathrm{eV}$ (labelled as N3), which are associated with nitrogen species in the $\mathrm{C}-\mathrm{N}=\mathrm{C}$, $\mathrm{N}-(\mathrm{C})_{3}$ and $\mathrm{C}-\mathrm{N}-\mathrm{H}$ groups of melon, respectively. ${ }^{2-3}$ Negligible changes in the binding energies of $\mathrm{C} 1 \mathrm{~s}$ and $\mathrm{N} 1 \mathrm{~s}$ core electrons as seen from Table $\mathrm{S} 2$ suggest that the chemical states of both carbon and nitrogen in Ar-temp and Ar-640-Air-temp are the same as those in bulk g- $\mathrm{C}_{3} \mathrm{~N}_{4}$.

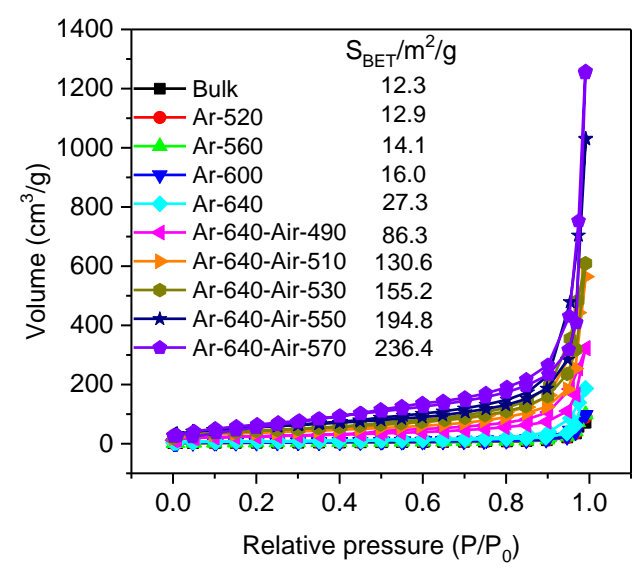

Figure S6. Nitrogen adsorption-desorption isotherms and the specific surface areas of various $\mathrm{g}-\mathrm{C}_{3} \mathrm{~N}_{4}$ materials. 



Figure S7. MS spectra of (a) $\mathrm{CO}_{2}(\mathrm{~m} / \mathrm{z}=44)$ and (b) NO $(\mathrm{m} / \mathrm{z}=30)$ during TG-DSC-MS measurement of Ar640 in $\mathrm{O}_{2} / \mathrm{Ar}(\mathrm{v} / \mathrm{v}=1 / 9)$ flow at 490 and $570{ }^{\circ} \mathrm{C}$, respectively.
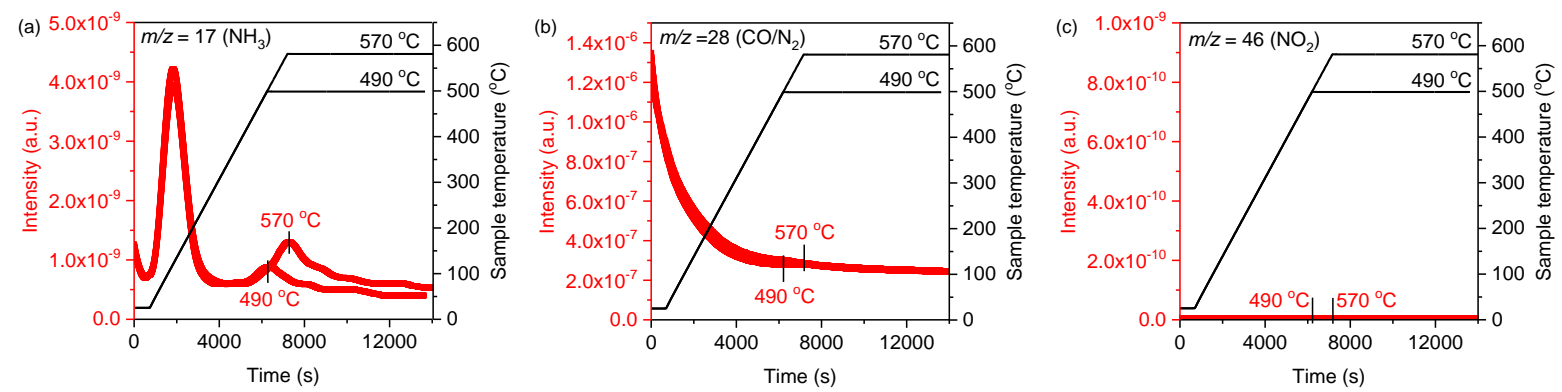

Figure S8. MS spectra of (a) $\mathrm{NH}_{3}(m / z=17)$, (b) $\mathrm{CO} / \mathrm{N}_{2}(\mathrm{~m} / \mathrm{z}=28)$ and (c) $\mathrm{NO}_{2}(\mathrm{~m} / \mathrm{z}=46)$ during TG-DSC-MS measurement of $\mathrm{Ar}-640$ in $\mathrm{O}_{2} / \mathrm{Ar}(\mathrm{v} / \mathrm{v}=1 / 9)$ flow at 490 and $570{ }^{\circ} \mathrm{C}$, respectively. Note that the release of $\mathrm{NH}_{3}$ at ca. $100{ }^{\circ} \mathrm{C}$ in plot a most likely derives from the terminal $\mathrm{NH}_{2} / \mathrm{NH}$ impurities which does not contribute to the formation of intralayer hydrogen bonds, and thus is not the concern. 

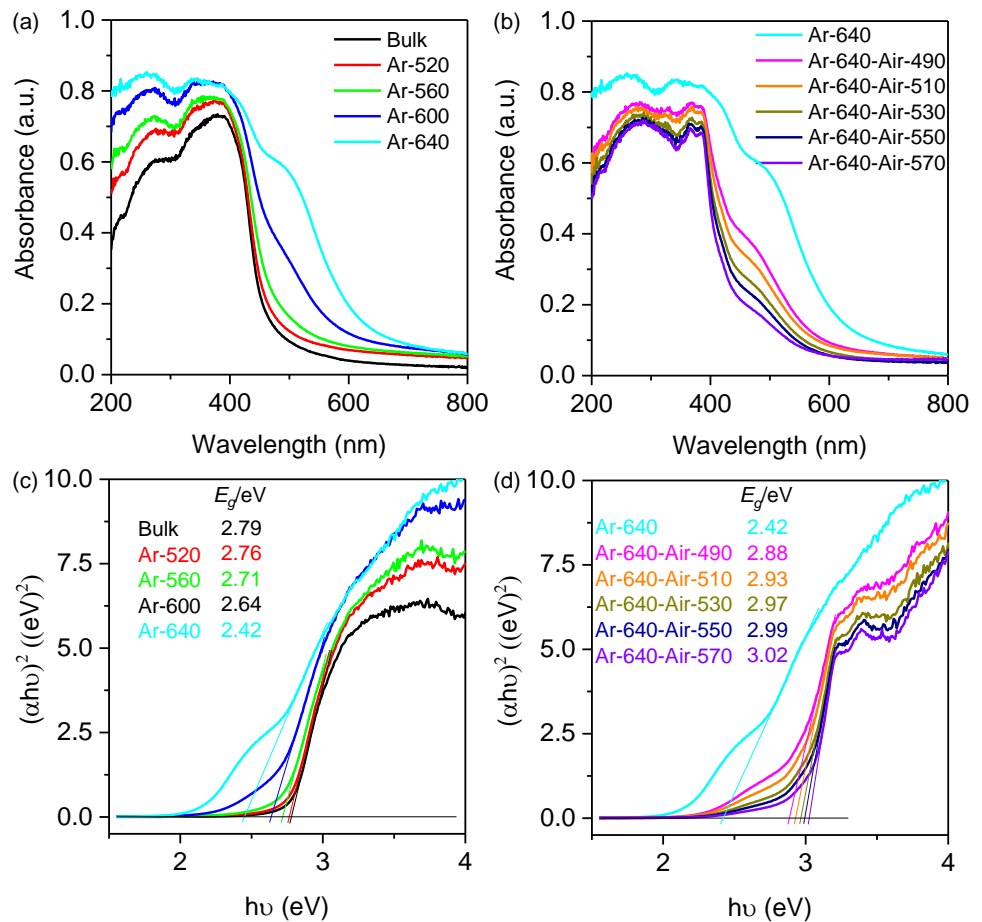

Figure S9. (a and b) UV-vis DRS spectra and (c and d) the corresponding Tauc plots of various $\mathrm{g}-\mathrm{C}_{3} \mathrm{~N}_{4}$ materials.

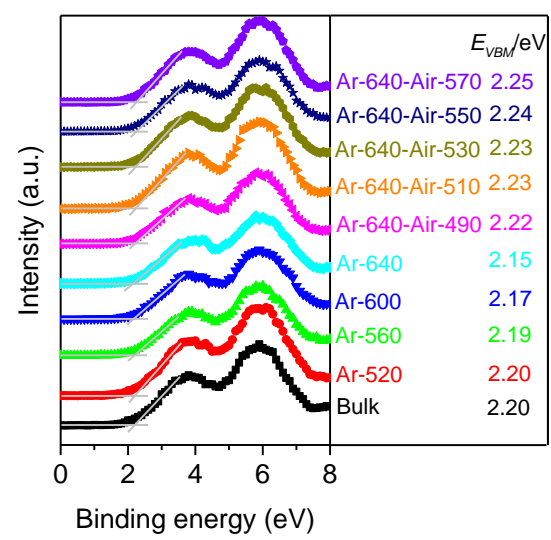

Figure S10. Valance band XPS spectra of various $\mathrm{g}^{-} \mathrm{C}_{3} \mathrm{~N}_{4}$ materials $\left(E_{F}=0 \mathrm{eV}\right)$. 
(a) $\mathrm{C}_{24} \mathrm{H}_{12} \mathrm{~N}_{36}\left(\mathrm{C}_{3} \mathrm{H}_{1.5} \mathrm{~N}_{4.5}\right)$
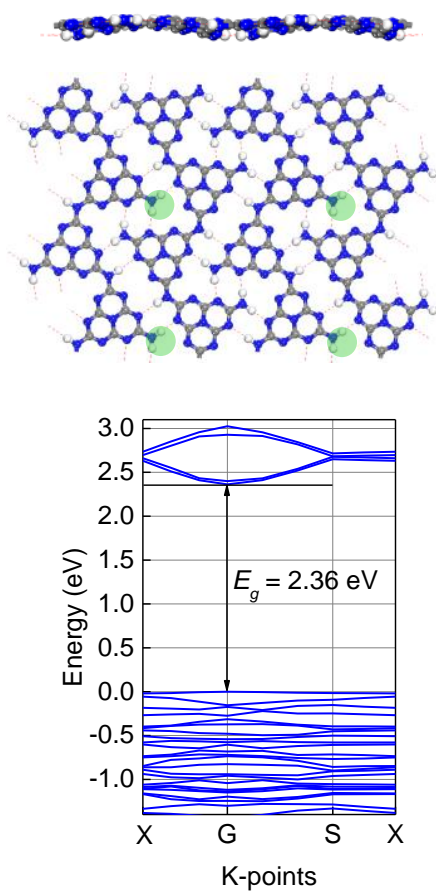

(b) $\mathrm{C}_{24} \mathrm{H}_{11} \mathrm{~N}_{35}\left(\mathrm{C}_{3} \mathrm{H}_{1.375} \mathrm{~N}_{4.375}\right)$
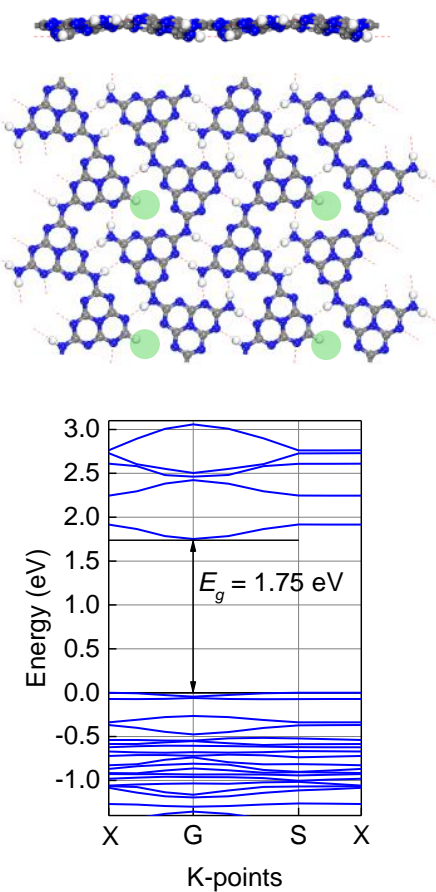

Figure S11. Molecular structures and calculated band structures of (a) monolayer $\mathrm{C}_{24} \mathrm{H}_{12} \mathrm{~N}_{36}$ (melon) and (b) $\mathrm{C}_{24} \mathrm{H}_{11} \mathrm{~N}_{35}$. $\mathrm{C}_{24} \mathrm{H}_{12} \mathrm{~N}_{36}$ and $\mathrm{C}_{24} \mathrm{H}_{11} \mathrm{~N}_{35}$ represent the incompletely condensed g- $\mathrm{C}_{3} \mathrm{~N}_{4}$ and that with partial loss of intralayer $\mathrm{NH}_{2} / \mathrm{NH}$ groups, respectively.
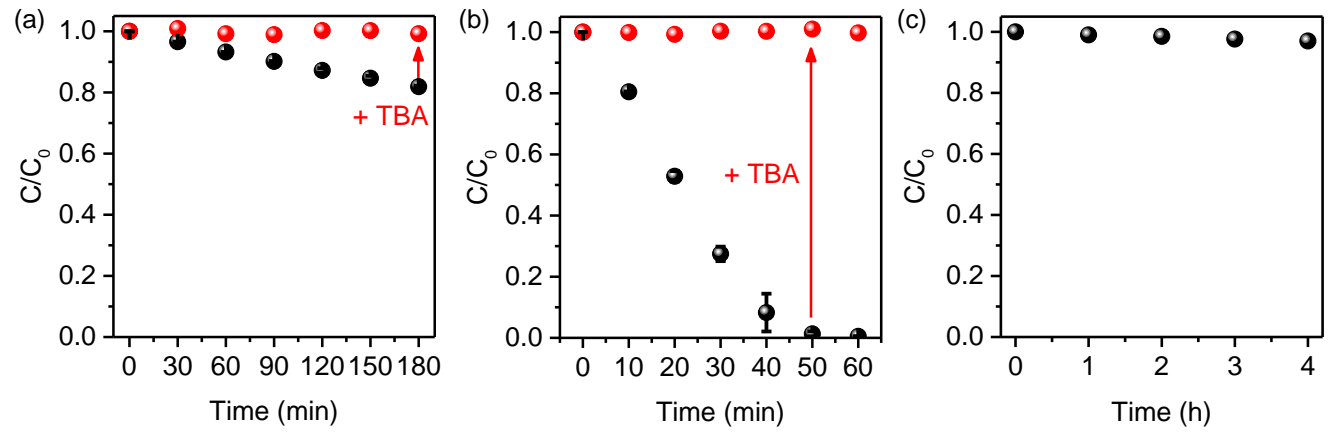

Figure S12. (a-b) Impact of $100 \mathrm{mM}$ tert-butyl alcohol (TBA) on OA degradation by photocatalytic oxidation (plot a) and photocatalytic ozonation (plot b) upon Ar-640-Air-550. (c) The concentration change of OA during Vis $/ \mathrm{N}_{2} / \mathrm{Ar}-640$-Air-550/100 $\mathrm{mM} \mathrm{AgNO} 3$ process (continuous $\mathrm{N}_{2}$ bubbling is to eliminate dissolved $\mathrm{O}_{2}$ and derived ROS; $100 \mathrm{mM} \mathrm{Ag}{ }^{+}$is added to trap $\mathrm{CB}-\mathrm{e}^{-}$, thus leaving more $\mathrm{h}^{+}$separated). 


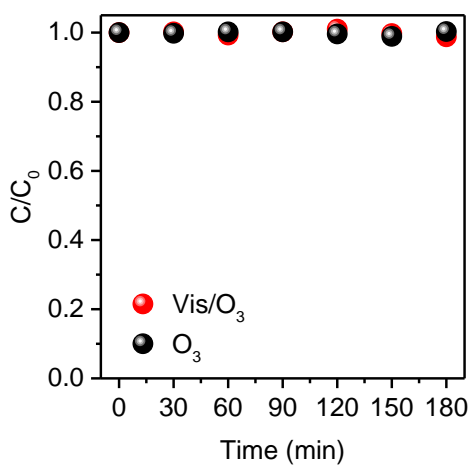

Figure S13. Change of OA concentration during $\mathrm{O}_{3}$ or $\mathrm{Vis} / \mathrm{O}_{3}$ treatment.
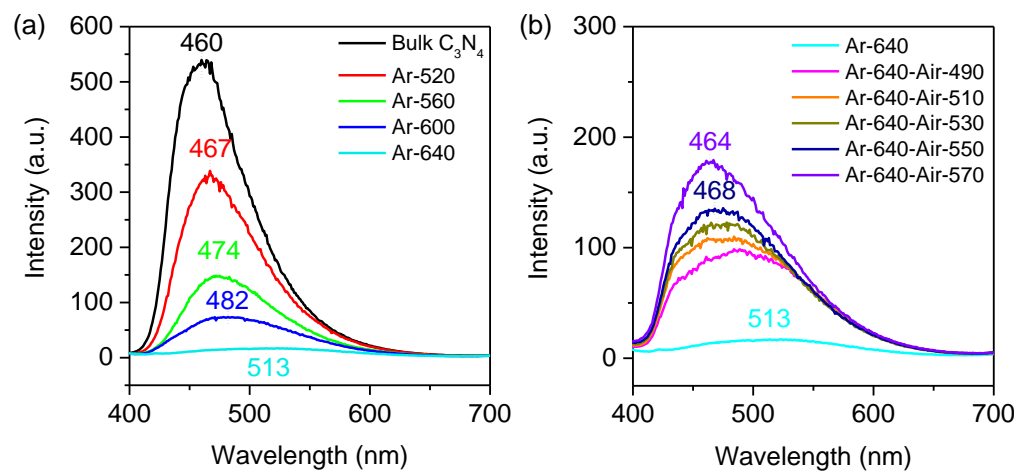

Figure S14. Photoluminescence spectra of (a) Ar-temp and (b) Ar-640-Air-temp samples.

Table S3. Ratios of $\left[\left(\mathrm{CB}-\mathrm{e}^{-}\right)_{\text {reactive }}\right]_{\mathrm{rel}} /\left[\left(\mathrm{CB}-\mathrm{e}^{-}\right)_{\text {total }}\right]_{\mathrm{rel}}$ using $\mathrm{O}_{2}$ or $\mathrm{O}_{3}$ as the $\mathrm{CB}-\mathrm{e}^{-}$trap, respectively

\begin{tabular}{|c|c|c|}
\hline \multirow{2}{*}{ Catalyst } & \multicolumn{2}{|c|}{$\left[\left(\mathrm{CB}-\mathrm{e}^{-}\right)_{\text {reactive }}\right]_{\mathrm{rel}} /\left[\left(\mathrm{CB}-\mathrm{e}^{-}\right)_{\text {total }}\right]_{\mathrm{rel}}$} \\
\hline & $\mathrm{O}_{2}$ as $\mathrm{CB}-\mathrm{e}^{-} \operatorname{trap}^{[\mathrm{a}]}$ & $\mathrm{O}_{3}$ as $\mathrm{CB}-\mathrm{e}^{-} \operatorname{trap}^{[\mathrm{b}]}$ \\
\hline Bulk & $32.4 \%$ & $53.4 \%$ \\
\hline Ar-640 & $3.1 \%$ & $8.1 \%$ \\
\hline Ar-640-Air-550 & $36.6 \%$ & $74.4 \%$ \\
\hline Ar-640-Air-570 & $36.8 \%$ & $75.3 \%$ \\
\hline
\end{tabular}

[a] Determined by height of red pillar/sum of the heights of red and grey pillars in Figure 6e.

[b] Determined by height of blue pillar/sum of the heights of blue and grey pillars in Figure 6e. 


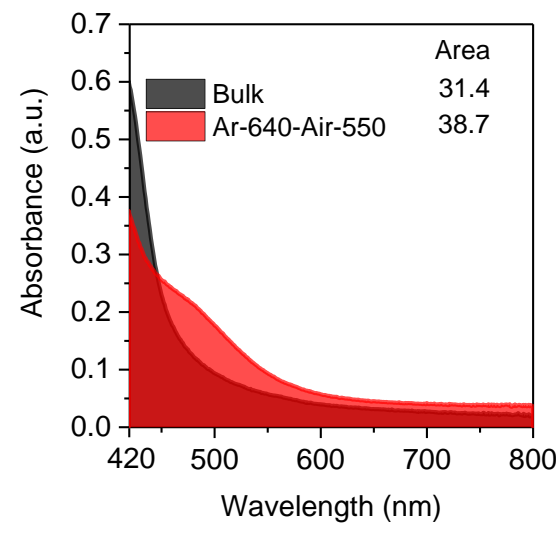

Figure S15. Comparison of integral areas of UV-vis absorption spectra between bulk $\mathrm{g}-\mathrm{C}_{3} \mathrm{~N}_{4}$ and Ar-640-Air550.

Apart from the light source energy and band gap, the intrinsic charge carrier concentration $\left(n_{i}\right)$ in the semiconductor also affects the photon-to-electron conversion, which is dependent of $E_{g}$, temperature, $N_{C}$ and $N_{V}$ (the effective density of states located at the CB and VB edges, respectively). ${ }^{4} N_{C}$ and $N_{V}$ can be significantly affected by the type and number of defects/impurities in the material.

$$
n_{\mathrm{i}}=\sqrt{n p}=\sqrt{N_{\mathrm{C}} N_{\mathrm{V}}} \mathrm{e}^{-E_{\mathrm{G}} / 2 k T}
$$

In most cases (constant temperature, similar type and number of defects/impurities), the smaller the $E_{g}$ of a semiconductor, the stronger the light absorption capacity (i.e., the larger the integral area of light absorption spectrum) ${ }^{5-6}$ However, the comparison between bulk g- $\mathrm{C}_{3} \mathrm{~N}_{4}$ and Ar-640-Air-550 is a special case. Ar-640-Air550 with a larger band gap exhibits relatively superior light absorption capacity in the experimental region of 420-800 nm. This could be explained by the introduced defects (that impact $N_{C}$ and $N_{V}$ values) in Ar-640-Air550 due to the two-step treatment (calcination of bulk g- $\mathrm{C}_{3} \mathrm{~N}_{4}$ in $\mathrm{Ar}$ at $640{ }^{\circ} \mathrm{C}$ and further in air at $550{ }^{\circ} \mathrm{C}$ ), endowing it with more enough intrinsic charge carriers to be excited (higher $n_{i}$ ) though the minimum excitation energy $\left(E_{g}\right)$ needed is higher. Therefore, to be precise, it is the area of light absorption spectrum that governs the number of photoexcited charge carriers. However, considering that band gap is a widespread term, and in most cases is negatively related to the integral area of light absorption spectrum, we still use band gap as the descriptor while add "the area of light absorption spectrum" as a supplementary statement. 




DMPO-OOH

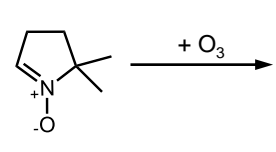

DMPO
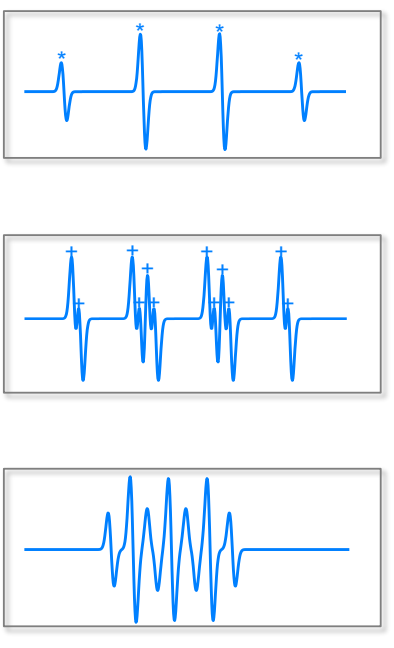

Figure S16. Structures and EPR signals of DMPO-OH and DMPO-OOH adducts formed by trapping ${ }^{\circ} \mathrm{OH}$ and $\cdot \mathrm{O}_{2}{ }^{-}$radicals with DMPO, and DMPOX formed by oxidation of DMPO with $\mathrm{O}_{3}$.

\section{References}

(1) Cui, Y.; Zhang, J.; Zhang, G.; Huang, J.; Liu, P.; Antonietti, M.; Wang, X. Synthesis of Bulk and Nanoporous Carbon Nitride Polymers from Ammonium Thiocyanate for Photocatalytic Hydrogen Evolution. $J$. Mater. Chem. 2011, 21, 13032-13039.

(2) Li, J.; Shen, B.; Hong, Z.; Lin, B.; Gao, B.; Chen, Y. A Facile Approach to Synthesize Novel OxygenDoped g- $\mathrm{C}_{3} \mathrm{~N}_{4}$ with Superior Visible-Light Photoreactivity. Chem. Commun. 2012, 48, 12017-12019.

(3) Zhang, J.; Zhang, M.; Zhang, G.; Wang, X. Synthesis of Carbon Nitride Semiconductors in Sulfur Flux for Water Photoredox Catalysis. ACS Catal. 2012, 2, 940-948.

(4) Baliga, B. J. Fundamentals of Power Semiconductor Devices; Springer: New York, 2008.

(5) Zhang, G.; Zhang, M.; Ye, X.; Qiu, X.; Lin, S.; Wang, X. Iodine Modified Carbon Nitride Semiconductors as Visible Light Photocatalysts for Hydrogen Evolution. Adv. Mater. 2014, 26, 805-809.

(6) Zhang, J.; Zhang, M.; Lin, S.; Fu, X.; Wang, X. Molecular Doping of Carbon Nitride Photocatalysts with Tunable Bandgap and Enhanced Activity. J. Catal. 2014, 310, 24-30. 